NBER WORKING PAPER SERIES

OPEN BORDERS IN THE EUROPEAN UNION AND BEYOND:

MIGRATION FLOWS AND LABOR MARKET IMPLICATIONS

\author{
John Kennan \\ Working Paper 23048 \\ http://www.nber.org/papers/w23048 \\ NATIONAL BUREAU OF ECONOMIC RESEARCH \\ 1050 Massachusetts Avenue \\ Cambridge, MA 02138 \\ January 2017
}

This paper was presented at the Economic Policy Panel meeting in Florence, October 2015. I thank Sascha Becker, Ted Bergstrom, Gino Gancia, Richard Lipsey and many seminar participants for helpful comments. The views expressed herein are those of the author and do not necessarily reflect the views of the National Bureau of Economic Research.

NBER working papers are circulated for discussion and comment purposes. They have not been peer-reviewed or been subject to the review by the NBER Board of Directors that accompanies official NBER publications.

(C) 2017 by John Kennan. All rights reserved. Short sections of text, not to exceed two paragraphs, may be quoted without explicit permission provided that full credit, including $\odot$ notice, is given to the source. 
Open Borders in the European Union and Beyond: Migration Flows and Labor Market Implications John Kennan

NBER Working Paper No. 23048

January 2017

JEL No. E25,F22,J61

\section{ABSTRACT}

In 2004, the European Union admitted 10 new countries, and wages in these countries were generally well below the levels in the existing member countries. Citizens of these newlyadmitted countries were subsequently free to take jobs anywhere in the EU, and many did so. In 2015, a large number of refugees from Syria and other broken countries sought to migrate to EU countries (along very dangerous routes), and these refugees were met with fierce resistance, at least in some places. This paper seeks to understand the labor market implications of allowing free migration across borders, with particular reference to the EU. The aim is to quantify the migration flows associated with EU enlargement, and to analyze the extent to which these flows affected equilibrium wages. The main conclusion is that the real wage effects are small, and the gains from open borders are large.

John Kennan

Department of Economics

University of Wisconsin

1180 Observatory Drive

Madison, WI 53706

and NBER

jkennan@ssc.wisc.edu 


\title{
Open Borders in the European Union and Beyond: Migration Flows and Labor Market Implications
}

\author{
John Kennan*
}

September 2016

\begin{abstract}
In 2004, the European Union admitted 10 new countries, and wages in these countries were generally well below the levels in the existing member countries. Citizens of these newlyadmitted countries were subsequently free to take jobs anywhere in the EU, and many did so. In 2015, a large number of refugees from Syria and other broken countries sought to migrate to EU countries (along very dangerous routes), and these refugees were met with fierce resistance, at least in some places. This paper seeks to understand the labor market implications of allowing free migration across borders, with particular reference to the EU. The aim is to quantify the migration flows associated with EU enlargement, and to analyze the extent to which these flows affected equilibrium wages. The main conclusion is that the real wage effects are small, and the gains from open borders are large.
\end{abstract}

\section{Introduction}

In 2004, the European Union admitted 10 new countries, and the wage levels in most of these countries were far below the levels in most of the existing member countries. Citizens of these newly-admitted countries were subsequently free to take jobs anywhere in the EU, and many did so. This paper seeks to understand the labor market implications of allowing free migration across borders, with particular reference to the EU. The aim is to quantify the migration flows associated with EU enlargement, and to analyze the extent to which these flows affected equilibrium wages.

This paper is about long-run effects of open borders, with very limited discussion of dynamics. Obviously, short-run effects are also important. But it can reasonably be argued that short-run effects tend to get too much attention in policy discussions. Given the difficulty of actually changing economic policies in practice, there is a lot to be said for making recommendations based on longrun considerations, with the idea that if the recommended policy is actually implemented, it will have lasting effects.

\footnotetext{
${ }^{*}$ University of Wisconsin-Madison and NBER University of Wisconsin-Madison and NBER; 1180 Observatory Drive, Madison, WI 53706, jkennan@ssc.wisc.edu. This paper was presented at the Economic Policy Panel meeting in Florence, October 2015. I thank Sascha Becker, Ted Bergstrom, Gino Gancia, Richard Lipsey and many seminar participants for helpful comments.
} 
Figure 1: Labor Allocation Effects

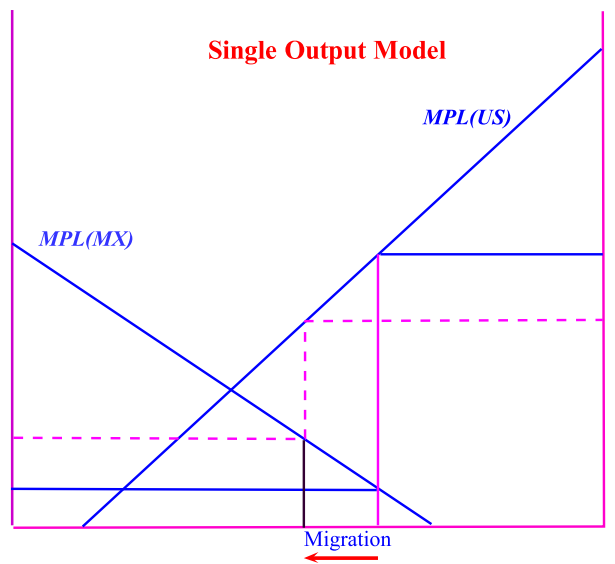

\section{Literature}

Hamilton and Whalley (1984) initiated the quantitative analysis of the costs of immigration restrictions. Their analysis (and subsequent work by Moses and Letnes (2004) and Iregui (2005), for example) was based on a multi-country version of the model illustrated in Figure $1 .{ }^{1}$ This is a standard textbook model of a segmented labor market (used for example to show the relative wage effects associated with unions). If two labor markets (say Mexico and the U.S.) have different downward-sloping curves showing the marginal product of labor as a function of the number of workers employed (here the number of workers in Mexico is measured from left to right, and the number in the U.S. is measured from right to left), then migration from Mexico to the U.S. reduces the wage in the U.S. and increases the wage in Mexico (the initial position being indicated by the solid lines, and the final position by the dashed lines). Since total output in each country is the area under the marginal product curve, migration raises total output. In the Hamilton and Whalley (1984) analysis, the result when immigration restrictions are removed is at the point where marginal products are equal, and total output is maximal. ${ }^{2}$

Hamilton and Whalley (1984) divide the world economy into 7 regions (EEC, U.S., Japan, other developed countries, OPEC, LDCs and Newly Industrialized Countries). Each region has its own CES technology, with different TFP levels, and different elasticities of substitution between capital and labor. The elasticities are set at "extraneous" values (meaning that calculations are made for a range of possible values), and the TFP levels are inferred from the data (World Bank data on GNP and population, and factor shares data from U.N sources). The results indicate that there are massive costs due to labor misallocation: total world output could be roughly doubled if all immigration restrictions were removed.

\footnotetext{
${ }^{1}$ See Bhagwati (1984)

${ }^{2}$ In exactly the same way, union relative wage effects are understood as the result of limiting the number of workers in one sector, which drives up the marginal product, while pushing more workers into the nonunion sector, which drives down the marginal product there.
} 
There are two major limitations of this segmented labor market model, in the present context. One is that the people in the model are not attached to any particular place, whereas there is a great deal of evidence indicating that, other things equal, most people would rather live their lives in the place where they grew up. Thus in the absence of immigration restrictions, one would not expect that wages would be equalized across countries, but rather that in the new equilibrium, every potential migrant would view the wage gain from moving to a high-wage country as insufficient to offset the cost of living away from home. The implied increase in output would then be less than the maximal amount (i.e. the amount calculated by Hamilton and Whalley (1984)), and even this increase overstates the gains from relaxing immigration restrictions, because it neglects the migration cost. ${ }^{3}$

The second limitation is that there is no consideration of the extent to which wage differences are arbitraged through product markets. Hamilton and Whalley (1984) acknowledged this, with the comment that "most trade economists appear to regard factor price equalization as a theoretical possibility rather than an empirical proposition", and proceeded to use a model in which only a single composite consumption good is produced, so that the factor price equalization theorem is moot. But of course the same comment applies to the idea that there is only one consumption good. The factor price equalization theorem does not apply directly in models which assume that every firm produces a distinct good, as in Dixit and Stiglitz (1977) and Krugman (1980), but product market arbitrage also implies strong restrictions on cross-country wage differences in such models. ${ }^{4}$

The Klein and Ventura (2009) analysis differs from Hamilton and Whalley (1984) in that the gains from migration are attributed to differences in TFP (as opposed to differences in the numbers of workers allocated to each country). The model used in Kennan (2013) attributes wage differences to differences in labor productivity; in this model the factor price equalization theorem holds when labor is measured in efficiency units, as in Trefler (1993). In contrast to the Klein-Ventura model, the gains have nothing to do with reallocating capital across countries, because it is assumed, in line with the evidence presented by Caselli and Feyrer (2007), that there are no differences in the productivity of capital, and factor price equalization implies that the return to capital is the same in all countries. ${ }^{5}$

\footnotetext{
${ }^{3}$ For example, the marginal migrant is more productive after migrating, but has a net gain of zero.

${ }^{4}$ For example, in the basic model in Krugman (1980), and also in the Melitz (2003) model, wages are equal across countries, because everything is symmetric. When transport costs are introduced, wages are higher in larger countries. Each good is consumed in all countries, and if production is moved to a larger country, the cost of delivering the good to consumers is reduced (because the consumers are closer). This pushes down the wage in smaller countries, to the point where the lower wage just offsets the higher transport cost. But transport costs are hardly a plausible explanation for the huge cross-country wage differences seen in the data.

${ }^{5}$ Even this modified version of the factor price equalization theorem is viewed skeptically as an empirical proposition by trade economists - see Davis and Weinstein (2004), for example. One reason for this skepticism, as explained by Goldberg and Pavcnik (2007), is that there is no evidence that the increased exposure of developing countries to international trade seen in recent years has led to a reduction in the skill premium. But of course no amount of evidence can repeal a theorem, and there seems to be no fully satisfactory model that accounts for large cross-country differences in wages paid to workers whose output is sold in competitive international markets. At this point the efficiency units version of factor price equalization seems to be the best model available.
} 


\section{Data}

\subsection{Some Descriptive Statistics}

Since it was founded in 1958, the number of member countries in the European Union gradually increased from 6 to 28 , as shown in Table $1 .{ }^{6}$ Citizens of newly-admitted countries were free to move and work anywhere within the borders of the EU (although in some countries restrictions remained in place for a few years).

Table 1: EU Expansion

\begin{tabular}{|c|c|c|c|c|c|c|c||c|}
\hline \multicolumn{7}{c|}{ The European Union, 1958 - 2016 } & \\
\hline \hline 1958 & 1973 & 1981 & 1986 & 1995 & 2004 & 2007 & 2013 & 2017 \\
\hline Belgium & Denmark & Greece & Portugal & Austria & Poland & Bulgaria & Croatia & UK? \\
\hline France & Ireland & & Spain & Finland & Czech Republic & Romania & & \\
\hline Germany & UK & & & Sweden & Estonia & & & \\
\hline Italy & & & & & Hungary & & & \\
\hline Luxembourg & & & & & Latvia & & & \\
\hline Netherlands & & & & & Lithuania & & & \\
\hline & & & & & Slovenia & & & \\
\hline & & & & & Slovakia & & & \\
\hline & & & & & Cyprus & & & \\
\hline
\end{tabular}

Differences in real GDP per worker together with population numbers are shown in Figure $2 .{ }^{7}$

The EU expansion demonstrates that open borders do not imply massive population movements, even when there are large wage disparities across countries. People do move, in substantial numbers, but the vast majority of people choose to stay in their home country. This is illustrated in Figure 3, which shows the number of Polish-born people living in Poland in 2002 and 2009, and the number of Polish-born people living in the UK and in Sweden, from 1998 to 2014, as a percentage of the population of Poland in 2002. Although there was a large increase in the number of Polish people in the UK after Poland joined the EU (and a similar increase in Sweden, on a smaller scale), the number of Polish people living in Poland nevertheless increased by $1.3 \%$ between 2002 and 2009 (from $36,871,281$ to $37,337,408) .{ }^{8}$ Figure 3 shows similar results for Hungary; in this case the data for the UK are missing, but the same pattern is seen using data for Holland. It is clear from these plots that when Poland and Hungary joined the EU, many people from these countries decided to move to more attractive locations. But the net migration flows are small in relation to the populations of the sending countries: even in the case of Poland and the UK, the proportion of Polish people in the UK 10 years after Poland joined the EU was less than one quarter of one

\footnotetext{
${ }^{6}$ Greenland left the EU in 1985.

${ }^{7}$ The colors in this plot represent the year of EU entry (in rainbow order).

${ }^{8}$ These data are from http://ec.europa.eu/eurostat/web/products-datasets/-/migr_pop3ctb.
} 
Figure 2: Population and GDP per worker, EU

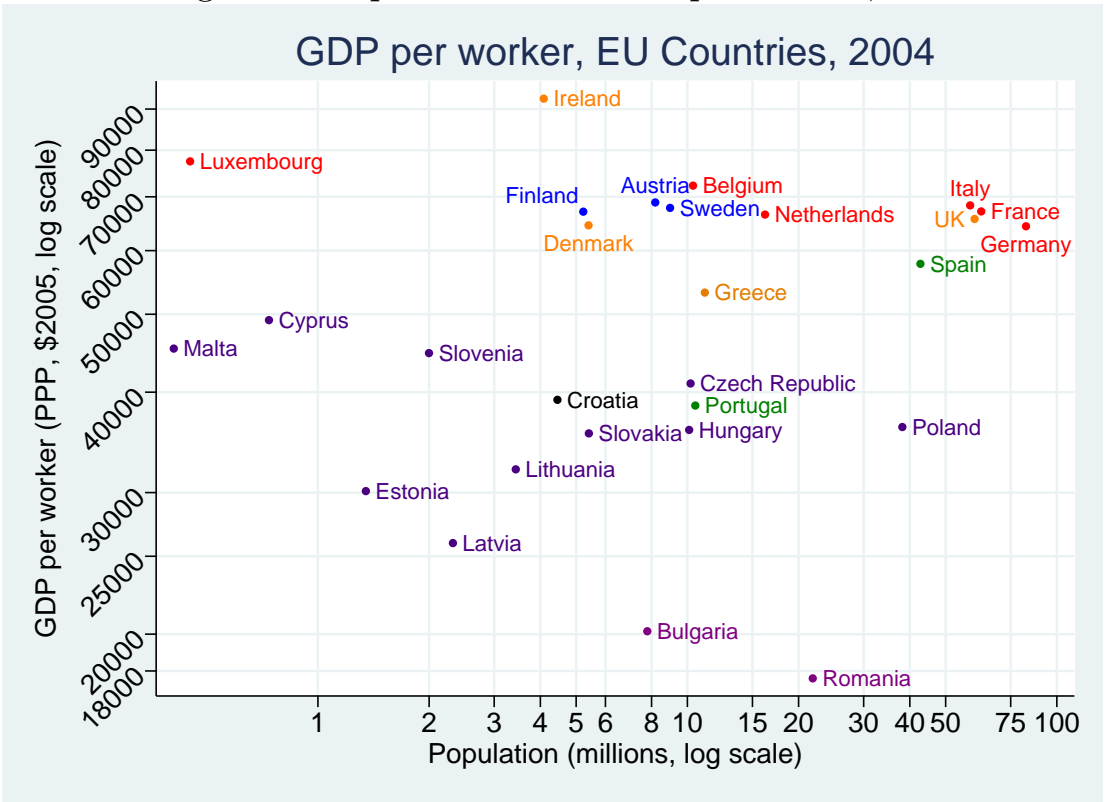

per cent. Figures 5 and 6 show similar patterns for Bulgaria and Romania. ${ }^{9}$

Figure 3: EU Migration: Poland, the UK and Sweden
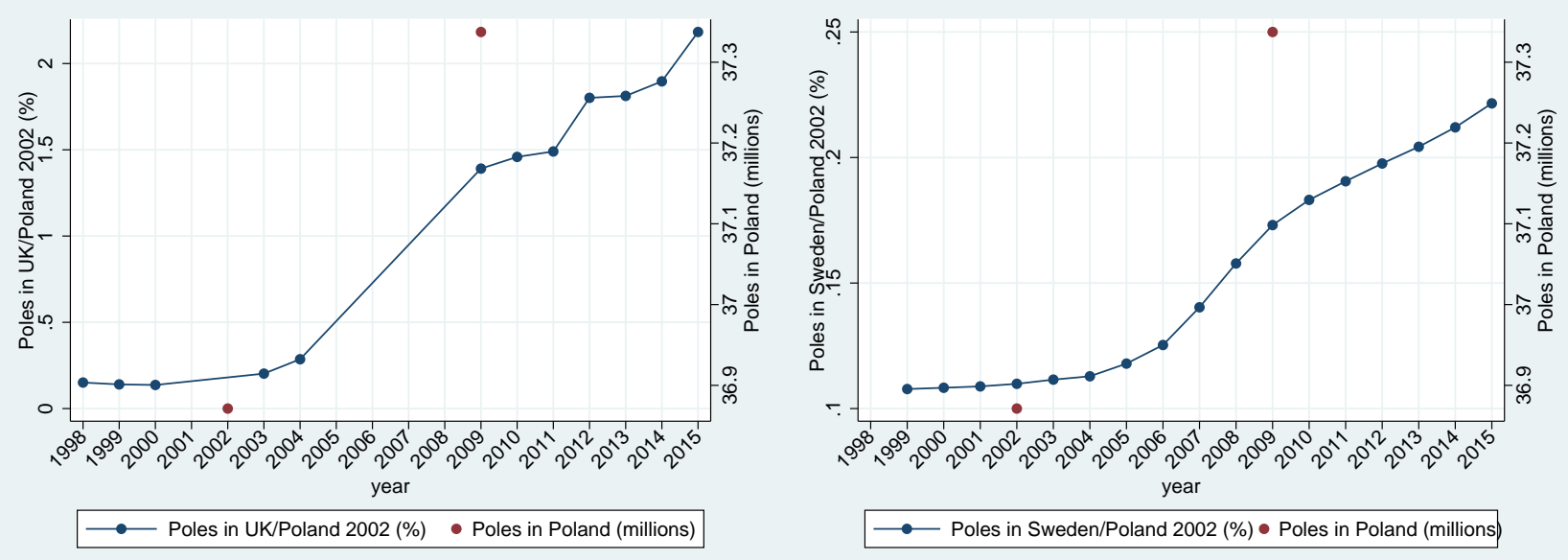

Another notable feature of these data is that the population movements are slow. Before Poland joined the EU, there were less than 100,000 Polish people in the UK. Five years later, that number had risen to about half a million. But after 10 years, the number was about three-quarters of a million, and apparently still rising. This is the pattern predicted by the simulation results in Kennan and Walker (2011). Migration decisions are affected by many things other than income differences. Even when income differences are large, the number of people close to the migration

\footnotetext{
${ }^{9}$ Some restrictions on migration from Bulgaria and Romania remained in place until January 1, 2014, notably in the UK
} 
Figure 4: EU Migration: Hungary, Holland and Sweden
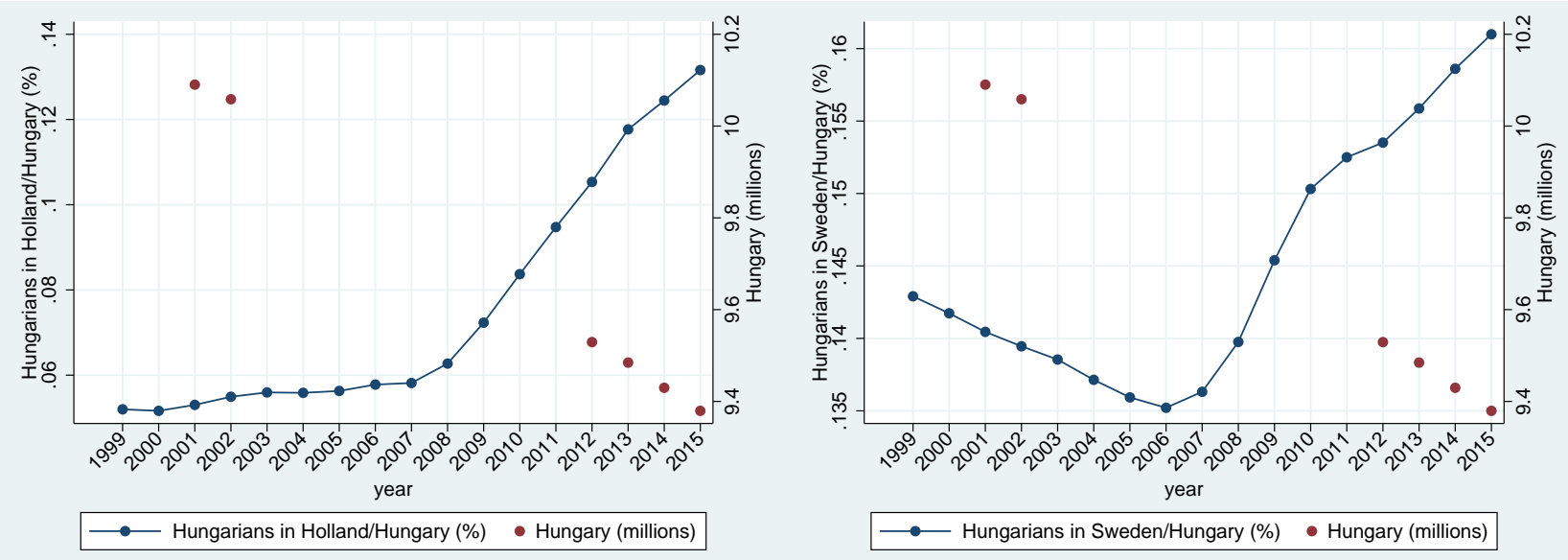

Figure 5: EU Migration: Bulgaria, Holland and Sweden
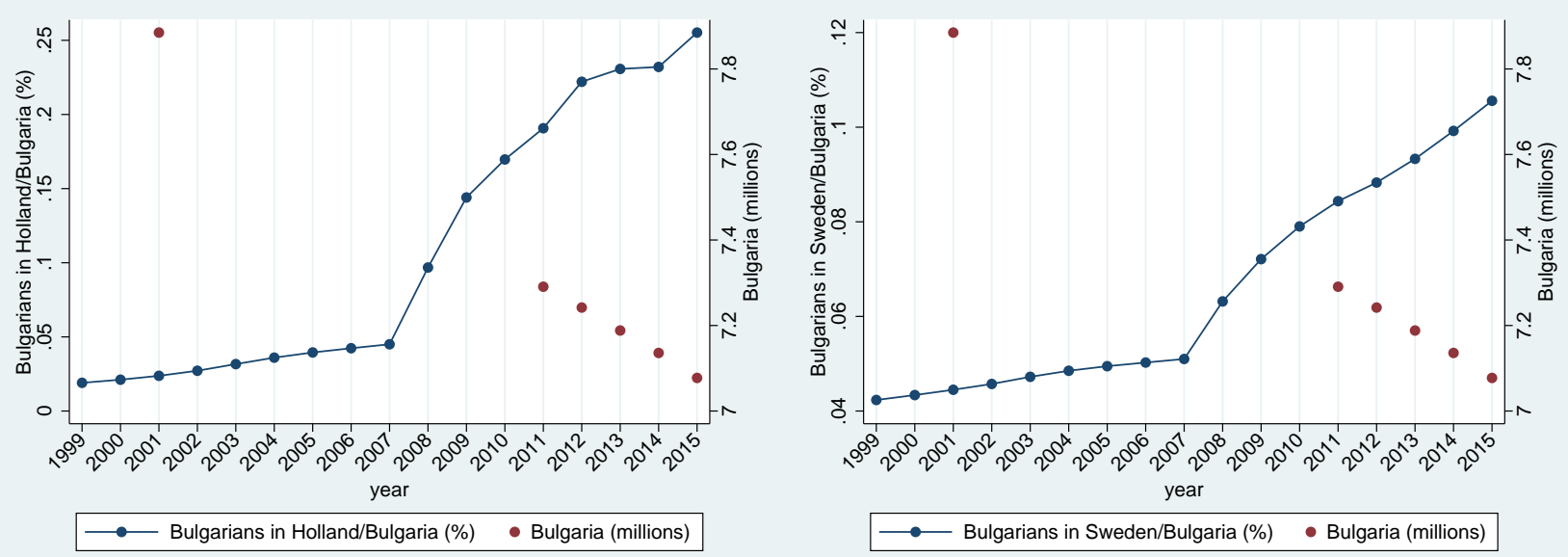

margin at any given time is likely to be relatively small, but if the differences persist, there will be a new flow of people close to the margin in each period, and the net flow of migrants slowly accumulates over time.

\section{Model}

The immigration literature has generally focused on the extent to which immigrants impose costs on workers in the destination country, either because increases in the supply of labor tend to depress wages (particularly for less skilled workers who compete more directly with immigrants), or because the taxes paid by immigrants do not fully cover the costs of their social welfare benefits. The typical 
Figure 6: EU Migration: Romania, UK and Spain
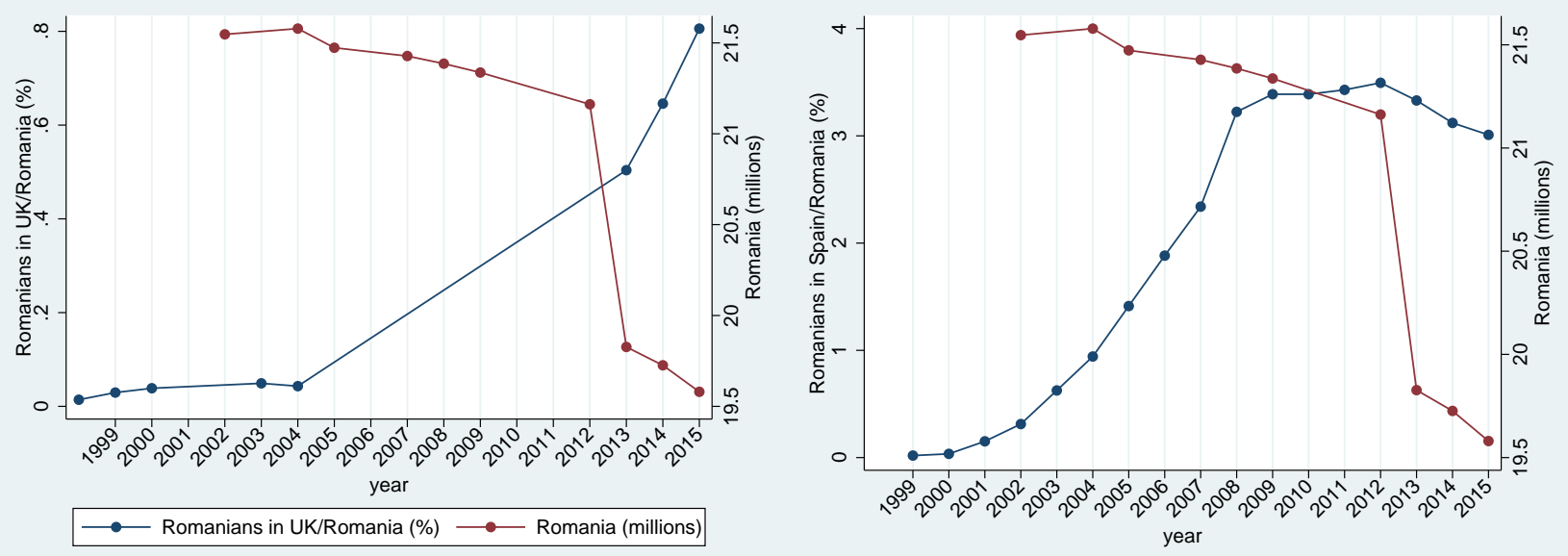

finding is that these costs are relatively small. ${ }^{10}$ The approach here is less chauvinistic, following Klein and Ventura (2007), Klein and Ventura (2009), Clemens (2011) and Kennan (2013): the emphasis is on the benefits associated with immigration, as perceived by the immigrants. As in Kennan (2013), the model assumes free trade in product markets, implying factor price equalization. The large observed differences in wages across countries are interpreted as the result of differences in the productivity of labor, implying large migration incentives even though wages are equalized in terms of efficiency units of labor. The model goes beyond Kennan (2013) by treated skilled and unskilled labor as imperfect substitutes, thus introducing the possibility that large flows of unskilled migrants can affect the skill premium. The main objective is to quantify the gains arising from expansion of the EU to include 13 new countries after 2004. In addition, the model is used to estimate the effects of this expansion on real wages in the EU countries.

The model has many produced goods, and it is assumed that the production technologies are similar, but not identical. Factor prices are equalized, but elasticities of substitution are not constant at the market level, even though the technology for each product is a (nested) CES.

\subsection{Factor Price Equalization with Labor-Augmenting Technology Differences}

Suppose there are $J$ countries, with common technologies, but different productivity levels. If the productivity differences are labor-augmenting (i.e. Harrod-neutral), then the technology for product $s$ in country $j$ can be specified as

$$
Q_{s}^{j}=F_{s}\left(K, a_{j} S, b_{j} U\right)
$$

\footnotetext{
${ }^{10}$ See, for example, Storesletten (2000), Card (2001), Piyapromdee (2015) and Colas (2016); for a more pessimistic view, see Borjas (2003).
} 
where $K$ is capital, and $\left(a_{j}, b_{j}\right)$ represent the efficiency units of skilled $(S)$ and unskilled $(U)$ labor per worker in country $j$.

Let $c_{s}^{0}$ be the unit cost function for product $s$ when the labor inputs are measured in efficiency units, so that the production function is $Q_{s}=F_{s}(K, S, U)$. Then the cost function for product $s$ in country $j$ is

$$
c_{s}^{j}(v, w)=c_{s}^{0}\left(v, \frac{w^{S}}{a_{j}}, \frac{w^{U}}{b_{j}}\right)
$$

where $w$ is the wage per efficiency unit of (skilled and unskilled) labor, and $v$ is the price of capital.

\subsubsection{Factor Price Equalization}

If there is free trade in the product markets, with no transportation costs, then the zero-profit condition implies

$$
p_{s}=c_{s}^{0}\left(v, \frac{w^{S}}{a_{j}}, \frac{w^{U}}{b_{j}}\right)
$$

If three products $\left\{s_{1}, s_{2}, s_{3}\right\}$ are produced in country $j$, then

$$
c_{s}^{0}\left(v, \frac{w^{S}}{a_{j}}, \frac{w^{U}}{b_{j}}\right)=p_{s}, s \in\left\{s_{1}, s_{2}, s_{3}\right\}
$$

These equations determine the factor prices in country $j$. If the marginal rates of technical substitution satisfy a single-crossing condition, the factor prices are uniquely determined. Then if country $\ell$ also produces these same products, the same equations determine factor prices in country $\ell$, with $a_{\ell}$ in place of $a_{j}$. This implies $v_{j}=v_{\ell}$, and

$$
\frac{w_{j}}{a_{j}}=\frac{w_{\ell}}{a_{\ell}}
$$

Thus

$$
\begin{aligned}
w_{j}^{S} & =a_{j} w_{0}^{S} \\
w_{j}^{U} & =b_{j} w_{0}^{U}
\end{aligned}
$$

where $w_{0}^{S}$ and $w_{0}^{U}$ are reference wage levels. In other words, wages are equal across countries when measured in efficiency units. This is true regardless of whether workers are allowed to move between countries (and it remains true if capital cannot move either). The point is that arbitrage in product markets implies (indirect) arbitrage in factor markets as well. In the standard HecksherOhlin model, factor price equalization implies that restrictions on international labor mobility are 
irrelevant, in the sense that there is no pecuniary incentive for workers to migrate. Here, in contrast, a worker who moves from a low-productivity country to a high-productivity country acquires more efficiency units of labor, and thus earnings rise even though the underlying price of labor is the same everywhere.

\subsection{General Equilibrium}

Given the factor prices, the prices of consumer goods are determined by the cost functions. The quantities consumed are determined by these goods prices, and by preferences and total income (where income depends on factor prices). Given the quantities to be produced, and the factor prices, producers determine the profit-maximizing factor quantities. This gives demand curves for the factors, and factor prices are determined so as to clear the factor markets.

For simplicity, it is assumed that: (1) preferences are identical in all countries, and are described by a loglinear utility function with expenditure share parameters $\theta_{s}$; and (2) the production function for each good is a nested CES, and is the same in all countries, with substitution elasticities that are the same for all goods (and with the understanding that the labor input is measured in efficiency units). The consumption goods are produced using capital and labor, where labor is a composite of skilled and unskilled labor, and where the skill mix is allowed to differ across products.

It is also assumed that each worker supplies one time-unit of labor (inelastically). This time-unit implies different amounts of effective labor in different countries, for two reasons: human capital endowments $h_{j}$ may differ across countries, and each unit of human capital in country $j$ means $a_{j}^{S}$ efficiency units of skilled labor, or $a_{j}^{U}$ efficiency units of unskilled labor.

The nested CES treats labor as a composite of two components, skilled and unskilled. The composite is a power-linear function of skilled and unskilled labor ${ }^{11}$ :

$$
L^{\kappa}=\gamma S^{\kappa}+(1-\gamma) U^{\kappa}
$$

with $\kappa<1$, where $\gamma \in[0,1]$ is a parameter reflecting the relative importance of skilled and unskilled labor in the composite. The elasticity of substitution between skilled and unskilled labor is $\zeta=\frac{1}{1-\kappa}$. It is assumed that this elasticity of substitution is the same for all products, but $\gamma$ may differ across products, with some products being more skill-intensive than others.

Output is a power-linear function of capital and (composite) labor. Write this as

$$
Y^{\rho}=\alpha K^{\rho}+(1-\alpha) L^{\rho}
$$

with $\rho<1$, where $\alpha \in[0,1]$ is a parameter reflecting the relative importance of capital and labor. The elasticity of substitution between skilled and unskilled labor is $\sigma=\frac{1}{1-\rho}$. It is assumed that this elasticity of substitution is the same for all products, but $\alpha$ may differ across products, with

\footnotetext{
${ }^{11}$ The function is linear if $\kappa=1$, and it is log-linear if $\kappa=0$.
} 
some products being more capital-intensive than others. Note that the production function for each good has constant returns.

The marginal product of labor $(M P L)$ satisfies

$$
Y^{\rho-1} M P L=(1-\alpha) L^{\rho-1}
$$

so

$$
\left(\frac{M P L}{1-\alpha}\right)^{\sigma}=A P L
$$

where $A P L=\frac{Y}{L}$ is the average product of labor.

Similarly

$$
\begin{aligned}
& \left(\frac{M P L_{u}}{1-\gamma}\right)^{\zeta}=\frac{L}{U} \\
& \left(\frac{M P L_{s}}{\gamma}\right)^{\zeta}=\frac{L}{S}
\end{aligned}
$$

where $M P L_{u}$ and $M P L_{s}$ are the marginal products of skilled and unskilled labor in the labor composite.

The price of good $r$ is given by the (power-linear) CES cost function

$$
p_{r}^{1-\sigma}=\alpha_{r}\left(\frac{v}{\alpha_{r}}\right)^{1-\sigma}+\left(1-\alpha_{r}\right)\left(\frac{W_{r}}{1-\alpha_{r}}\right)^{1-\sigma}
$$

where $W_{r}$ is the price of the labor composite in efficiency units, which is determined by the CES cost function for labor:

$$
W_{r}^{1-\zeta}=\gamma_{r}\left(\frac{w^{S}}{\gamma_{r}}\right)^{1-\zeta}+\left(1-\gamma_{r}\right)\left(\frac{w^{U}}{1-\gamma_{r}}\right)^{1-\zeta}
$$

The conditional factor demand functions are the derivatives of the cost functions, by Shephard's lemma. The derivatives are determined by

$$
\begin{aligned}
c_{r}^{-\sigma} \frac{\partial c_{r}}{\partial v} & =\left(\frac{v}{\alpha_{r}}\right)^{-\sigma} \\
c_{r}^{-\sigma} \frac{\partial c_{r}}{\partial W_{r}} & =\left(\frac{W_{r}}{1-\alpha_{r}}\right)^{-\sigma}
\end{aligned}
$$


The demands for unskilled and skilled labor are obtained from the labor cost function . Thus

$$
\begin{aligned}
W_{r}^{-\zeta} \frac{\partial W_{r}}{\partial w^{S}} & =\left(\frac{w^{S}}{\gamma_{r}}\right)^{-\zeta} \\
W_{r}^{-\zeta} \frac{\partial W_{r}}{\partial w^{U}} & =\left(\frac{w^{U}}{1-\gamma_{r}}\right)^{-\zeta}
\end{aligned}
$$

where $W_{r}$ is the unit price of the labor composite used in the production of good $r$. Thus the factor demands are given by

$$
\begin{aligned}
K_{r} & =Q_{r} c_{r}^{\sigma}\left(\frac{v}{\alpha_{r}}\right)^{-\sigma} \\
U_{r} & =L_{r} W_{r}^{\zeta}\left(\frac{w^{U}}{1-\gamma_{r}}\right)^{-\zeta} \\
S_{r} & =L_{r} W_{r}^{\zeta}\left(\frac{w^{S}}{\gamma_{r}}\right)^{-\zeta}
\end{aligned}
$$

\subsection{Equilibrium Characterization}

The equilibrium conditions can be described as follows. First the labor share in each industry $\left(\lambda_{r}\right)$ is given by

$$
\frac{1-\lambda_{r}}{\lambda_{r}}=\left(\frac{\alpha_{r}}{1-\alpha_{r}}\right)^{\sigma}\left(\frac{W_{r}}{v}\right)^{\sigma-1}
$$

and the share of skilled labor in total labor income in each industry $\left(\eta_{r}\right)$ is given by

$$
\frac{1-\eta_{r}}{\eta_{r}}=\left(\frac{1-\gamma_{r}}{\gamma_{r}}\right)^{\zeta}\left(\frac{w^{S}}{w^{U}}\right)^{\zeta-1}
$$

Skilled labor earnings in industry $r$ can be written as

$$
w^{S} S_{r}=\eta_{r} W_{r} L_{r}
$$

Similarly, labor cost in industry $r$ can be written as

$$
W_{r} L_{r}=\lambda_{r} p_{r} Q_{r}
$$

The quantities to be produced are determined by the expenditure shares $\theta_{r}$ applied to total income

$$
p_{r} Q_{r}=\theta_{r}\left(v K_{0}+w^{S} S_{0}+w^{U} U_{0}\right)
$$

where $S_{0}$ and $U_{0}$ are the aggregate amounts of skilled and unskilled labor in the world (in efficiency units), and $K_{0}$ is the aggregate amount of capital. 
Putting these pieces together gives skilled labor earnings in industry $r$ as

$$
w^{S} S_{r}=\eta_{r} \lambda_{r} \theta_{r}\left(v K_{0}+w^{S} S_{0}+w^{U} U_{0}\right)
$$

and adding over industries gives the market-clearing condition for skilled labor

$$
w^{S} \bar{S}=\sum_{r} \eta_{r} \lambda_{r} \theta_{r}\left(v K_{0}+w^{S} S_{0}+w^{U} U_{0}\right)
$$

with a similar equation for unskilled labor. Thus the market-clearing equations can be written as

$$
\begin{aligned}
& A_{S}(x)\left(1+x_{1}+x_{2}\right)=x_{1} \\
& A_{U}(x)\left(1+x_{1}+x_{2}\right)=x_{2}
\end{aligned}
$$

where

$$
x=\left(x_{1}, x_{2}\right)=\left(\frac{w^{S} S_{0}}{v K_{0}}, \frac{w^{U} U_{0}}{v K_{0}}\right)
$$

and

$$
\begin{aligned}
& A_{S}(x)=\sum_{r} \theta_{r} \lambda_{r}(x) \eta_{r}(x) \\
& A_{U}(x)=\sum_{r} \theta_{r} \lambda_{r}(x)\left(1-\eta_{r}(x)\right)
\end{aligned}
$$

To complete this characterization of the equilibrium conditions, it must be shown that the shares can be expressed in terms of $x$. The skilled labor share can immediately be written as

$$
\eta_{r}(x)=\frac{1}{1+\left(\frac{1-\gamma_{r}}{\gamma_{r}}\right)^{\zeta}\left(\frac{x_{1}}{x_{2}} \frac{U_{0}}{S_{0}}\right)^{\zeta-1}}
$$

To write the share of the labor composite as a function of $x$ first note that the factor price ratio in industry $r$ satisfies

$$
\left(\frac{W_{r}}{v}\right)^{1-\zeta}=\gamma_{r}^{\zeta}\left(x_{1} \frac{K_{0}}{S_{0}}\right)^{1-\zeta}+\left(1-\gamma_{r}\right)^{\zeta}\left(x_{2} \frac{K_{0}}{U_{0}}\right)^{1-\zeta}
$$

Thus

$$
\lambda_{r}(x)=\frac{1}{1+\left(\frac{\alpha_{r}}{1-\alpha_{r}}\right)^{\sigma}\left(\gamma_{r}^{\zeta}\left(x_{1} \frac{K_{0}}{S_{0}}\right)^{1-\zeta}+\left(1-\gamma_{r}\right)^{\zeta}\left(x_{2} \frac{K_{0}}{U_{0}}\right)^{1-\zeta}\right)^{\frac{\sigma-1}{1-\zeta}}}
$$

Adding the two market-clearing equations gives 


$$
\left(1+x_{1}+x_{2}\right) \sum_{r} \theta_{r} \lambda_{r}(x)=x_{1}+x_{2}
$$

so

$$
1-\sum_{r} \theta_{r} \lambda_{r}(x)=1-\frac{x_{1}+x_{2}}{1+x_{1}+x_{2}}
$$

and

$$
\sum_{r} \theta_{r}\left(1-\lambda_{r}(x)\right)=\frac{1}{1+x_{1}+x_{2}}
$$

Substituting this in the market-clearing equations gives

$$
\begin{aligned}
\sum_{r} \theta_{r} \lambda_{r}(x) \eta_{r}(x) & =x_{1} \sum_{r} \theta_{r}\left(1-\lambda_{r}(x)\right) \\
\sum_{r} \theta_{r} \lambda_{r}(x)\left(1-\eta_{r}(x)\right) & =x_{2} \sum_{r} \theta_{r}\left(1-\lambda_{r}(x)\right)
\end{aligned}
$$

and these equations can be rearranged as

$$
\begin{aligned}
\sum_{r} \theta_{r} \lambda_{r}(x)\left(\eta_{r}(x)+x_{1}\right)-x_{1} & =0 \\
\sum_{r} \theta_{r} \lambda_{r}(x)\left(1-\eta_{r}(x)+x_{2}\right)-x_{2} & =0
\end{aligned}
$$

Thus an equilibrium is a point $x=\left(x_{1}, x_{2}\right)$ that solves these two (nonlinear) equations. It is straightforward to show that a solution exists. But showing uniqueness by direct analysis of these equations is surprisingly difficult. And showing uniqueness indirectly using the economic structure that generates the equations is surprisingly easy, as is shown in the Appendix.

\subsection{Goods Prices}

The price ratio between any two consumer goods is given by

$$
\frac{p_{r}^{1-\sigma}}{p_{s}^{1-\sigma}}=\frac{\alpha_{r}\left(\frac{v}{\alpha_{r}}\right)^{1-\sigma}+\left(1-\alpha_{r}\right)\left(\frac{W_{r}}{1-\alpha_{r}}\right)^{1-\sigma}}{\alpha_{s}\left(\frac{v}{\alpha_{s}}\right)^{1-\sigma}+\left(1-\alpha_{s}\right)\left(\frac{W_{s}}{1-\alpha_{s}}\right)^{1-\sigma}}
$$




$$
\frac{p_{r}^{1-\sigma}}{p_{s}^{1-\sigma}}=\left(\frac{W_{r}}{W_{s}}\right)^{1-\sigma} \frac{\alpha_{r}^{\sigma}\left(\frac{v}{W_{r}}\right)^{1-\sigma}+\left(1-\alpha_{r}\right)^{\sigma}}{\alpha_{s}^{\sigma}\left(\frac{v}{W_{s}}\right)^{1-\sigma}+\left(1-\alpha_{s}\right)^{\sigma}}
$$

Thus an increase in the price of capital relative to labor implies an increase in the relative price of capital-intensive goods.

\subsection{Immigration and Wages}

The effective total supply of labor aggregated over countries is

$$
L_{0}=\sum_{j} a_{j} h_{j} N_{j}
$$

where $N_{j}$ is the labor force in country $j$. When workers move to countries where labor is more efficient, the effective supply of labor increases, and if the capital stock is taken as fixed, this reduces the capital-labor ratio. Thus if $M_{j k}$ workers migrate from $j$ to $k$, the change in the effective labor supply is

$$
\Delta \bar{L}=\sum_{j} \sum_{k}\left(a_{k} h_{k}-a_{j} h_{j}\right) M_{j k}
$$

The amount of effective labor time needed to earn enough to buy one unit of good $r$ is $\frac{p_{r}}{W_{r}}$. This is determined by

$$
\left(\frac{p_{r}}{W_{r}}\right)^{1-\sigma}=\alpha_{r}^{\sigma}\left(\frac{v}{W_{r}}\right)^{1-\sigma}+\left(1-\alpha_{r}\right)^{\sigma}
$$

and in the Cobb-Douglas case $(\sigma=1)$ this reduces to

$$
\log \left(\frac{p_{r}}{W_{r}}\right)=\alpha_{r} \log \left(\frac{v}{W_{r}}\right)-\alpha_{r} \log \left(\alpha_{r}\right)-\left(1-\alpha_{r}\right) \log \left(1-\alpha_{r}\right)
$$

The composite wage $W_{r}$ is given by

$$
W_{r}^{1-\zeta}=\gamma_{r}\left(\frac{w^{S}}{\gamma_{r}}\right)^{1-\zeta}+\left(1-\gamma_{r}\right)\left(\frac{w^{U}}{1-\gamma_{r}}\right)^{1-\zeta}
$$

and in the Cobb-Douglas case $(\zeta=1)$ this reduces to

$$
\log \left(W_{r}\right)=\gamma_{r} \log \left(\frac{w^{S}}{\gamma_{r}}\right)+\left(1-\gamma_{r}\right) \log \left(\frac{w^{U}}{1-\gamma_{r}}\right)
$$


Then in the case where the technology is Cobb-Douglas at both levels

$$
\log \left(p_{r}\right)=\alpha_{r} \log \left(\frac{v}{\alpha_{r}}\right)+\bar{\alpha}_{r} \gamma_{r} \log \left(\frac{w^{S}}{\gamma_{r}}\right)+\bar{\alpha}_{r} \bar{\gamma}_{r} \log \left(\frac{w^{U}}{\bar{\gamma}_{r}}\right)-\bar{\alpha}_{r} \log \bar{\alpha}_{r}
$$

where $\bar{\alpha}_{r}=1-\alpha_{r}$ and $\bar{\gamma}_{r}=1-\alpha_{r}$. This involves constant terms that can be ignored (since they don't change when the endowments change). Thus

$$
\log \left(p_{r}\right)=\alpha_{r} \log v+\bar{\alpha}_{r} \gamma_{r} \log w^{S}+\bar{\alpha}_{r} \bar{\gamma}_{r} \log w^{U}-\log \left(p_{r}^{0}\right)
$$

where

$$
\log \left(p_{r}^{0}\right)=\alpha_{r} \log \alpha_{r}+\bar{\alpha}_{r} \gamma_{r} \log \gamma_{r}+\bar{\alpha}_{r} \bar{\gamma}_{r} \log \bar{\gamma}_{r}+\bar{\alpha}_{r} \log \bar{\alpha}_{r}
$$

\subsection{Real Wages}

When immigration restrictions are relaxed, the capital-labor ratios and factor-price ratios change, and this leads to changes in real wages. These changes affect all countries in exactly the same way (regardless of whether they are sending or receiving countries). Factor price equalization holds both before and after the migration of labor, but migration reduces the wage per efficiency unit of labor (and therefore also reduces the wages of all workers who do not migrate).

The indirect utility function is the log of the real wage

$$
u^{*}=\sum_{r} \theta_{r} \log \left(\frac{w}{p_{r}}\right)
$$

Then (ignoring the constant terms) the indirect utilities for unskilled and skilled workers are

$$
\begin{aligned}
& u_{U}^{*}=\sum_{r} \theta_{r} \alpha_{r} \log \left(\frac{w^{U}}{v}\right)+\sum_{r} \theta_{r} \bar{\alpha}_{r} \gamma_{r} \log \left(\frac{w^{U}}{w^{S}}\right) \\
& u_{S}^{*}=\sum_{r} \theta_{r} \alpha_{r} \log \left(\frac{w^{S}}{v}\right)+\sum_{r} \theta_{r} \bar{\alpha}_{r} \bar{\gamma}_{r} \log \left(\frac{w^{S}}{w^{U}}\right)
\end{aligned}
$$

\subsubsection{Cobb-Douglas Technology}

The case of a Cobb-Douglas technology is a useful starting point. Suppose that $\sigma=\zeta=1$. If the utility function is

$$
U(q)=\prod_{r} q_{r}^{\theta_{r}}
$$

then indirect utility is real income, which is given by

$$
\log \left(y^{*}\right)=\log y-\sum_{r} \theta_{r} \log \left(p_{r}\right)
$$


where $y$ is income. If there are $n$ factors of production, then (ignoring constants)

$$
\log \left(p_{r}\right)=\sum_{i=1}^{n} \alpha_{i r} \log \left(w_{i}\right)
$$

where $w_{i}$ is the price of factor $i$, so

$$
\sum_{r} \theta_{r} \log \left(p_{r}\right)=\sum_{r=1}^{J} \theta_{r} \sum_{i=1}^{n} \alpha_{i r} \log \left(w_{i}\right)
$$

and this can be written as

$$
\sum_{r} \theta_{r} \log \left(p_{r}\right)=\sum_{i=1}^{n} \alpha_{i} \log \left(w_{i}\right)
$$

where

$$
\alpha_{i}=\sum_{r=1}^{J} \theta_{r} \alpha_{i r}
$$

with

$$
\sum_{i=1}^{n} \alpha_{i}=\sum_{r=1}^{J} \theta_{r} \sum_{i=1}^{n} \alpha_{i r}=1
$$

Then

$$
\log \left(y^{*}\right)=\log y-\sum_{i=1}^{n} \alpha_{i} \log \left(w_{i}\right)
$$

Also

$$
w_{i} x_{i r}=\alpha_{i r} p_{r} q_{r}
$$

and $p_{r} q_{r}=\theta_{r} Y$, where $Y$ is total (factor) income, so

$$
w_{i} x_{i r}=\alpha_{i r} \theta_{r} \sum_{k=1}^{n} w_{k} X_{k}
$$

where $X_{i}$ is the total endowment of factor $i$. Aggregating this over products gives

$$
w_{i} X_{i}=\alpha_{i} \sum_{k=1}^{n} w_{k} X_{k}
$$

This determines relative factor prices:

$$
\frac{w_{k} X_{k}}{w_{i} X_{i}}=\frac{\alpha_{k}}{\alpha_{i}}
$$


For a worker whose income is $w_{k}$, real income is given by

$$
\begin{aligned}
\log \left(y_{k}^{*}\right) & =\log \left(w_{k}\right)-\sum_{i=1}^{n} \alpha_{i} \log \left(w_{i}\right) \\
& =\sum_{i=1}^{n} \alpha_{i} \log \left(\frac{w_{k}}{w_{i}}\right)
\end{aligned}
$$

Then

$$
\log \left(y_{k}^{*}\right)=\sum_{i=1}^{n} \alpha_{i} \log \left(\frac{X_{i}}{X_{k}}\right)
$$

(where an additional constant term involving $\log \left(\frac{\alpha_{k}}{\alpha_{i}}\right)$ is ignored).

This gives an aggregation result: if there was a single product, the real wage would be computed in the same way. In other words, $y_{k}^{*}$ is just the marginal product of labor, because aggregate output is given by

$$
\log (Q)=\sum_{i=1}^{n} \alpha_{i} \log \left(X_{i}\right)
$$

Here the wage is proportional to the average product of labor, in the aggregate.

In the three factor case, the above expressions for real wages reduce to

$$
\begin{aligned}
& \log \left(w_{U}^{*}\right)=\alpha_{K} \log \left(\frac{K_{0}}{U_{0}}\right)+\alpha_{S} \log \left(\frac{S_{0}}{U_{0}}\right) \\
& \log \left(w_{S}^{*}\right)=\alpha_{K} \log \left(\frac{K_{0}}{S_{0}}\right)+\alpha_{U} \log \left(\frac{U_{0}}{S_{0}}\right)
\end{aligned}
$$

where

$$
\begin{aligned}
\alpha_{K} & =\sum_{r=1}^{J} \theta_{r} \alpha_{r} \\
\alpha_{S} & =\sum_{r=1}^{J} \theta_{r}\left(1-\alpha_{r}\right) \eta_{r} \\
\alpha_{U} & =\sum_{r=1}^{J} \theta_{r}\left(1-\alpha_{r}\right)\left(1-\eta_{r}\right)
\end{aligned}
$$

\subsection{Real Wage Effects in the Short Run and in the Long Run}

Migration increases the return on capital, since the effective capital-labor ratio decreases. In steady state equilibrium with a constant returns technology

$$
f^{\prime}\left(k^{*}\right)=\rho+\delta
$$


where $f^{\prime}$ is the marginal product of capital, $\rho$ is the rate of time preference, $\delta$ is the depreciation rate and $k^{*}$ is the effective capital-labor ratio. In the short run, migration increases the effective labor supply, so the capital-labor ratio falls below $k^{*}$, and the marginal product of capital rises above $\rho+\delta$. The investment rate therefore increases, and this continues until the effective capitallabor ratio returns to $k^{*}$, and the real wage returns to its original level. Thus migration does not reduce wages in the long run. One conclusion from the analysis in Kennan (2013) is that the effect of open borders on real wage rates is small (even in the short run, with capital held fixed). In a dynamic model, the effect on real wages would be very much attenuated, even in the short run. For example, in the Kennan and Walker (2011) model of internal migration within the U.S., it takes about 10 years before the response to a simulated (permanent) increase in the real wage in one location is more or less complete. Thus if immigration restrictions are removed gradually, in such a way that the effective labor supply grows at the same rate as the capital stock, then wages do not fall even in the short run.

\subsection{Migration Decisions}

One might initially expect that in a world with open borders, everyone would move to the most productive location. But this ignores the strong attachment to home locations that is evident in the data. ${ }^{12}$

For a worker at skill level $s$, let $a_{j s}=\frac{y_{j s}}{y_{0 s}} \leq 1$ be the level of income in the home location $\left(y_{j s}\right)$, relative to the highest income available elsewhere $\left(y_{0 s}\right)$, and assume that migration involves a utility $\operatorname{cost} \delta$, which is drawn from a distribution $F_{s}$. Since the utility function is loglinear, the indirect utility function can be expressed as $\log (y)$. Then it is optimal to stay in the home location if

$$
\log \left(y_{0 s}\right)-\delta \leq \log \left(y_{j s}\right)
$$

If the distribution of $\delta$ is exponential, $F_{s}(t)=1-e^{-\omega_{s} t}$, then the probability of staying is

$$
\operatorname{Prob}\left(\delta \geq \log \left(\frac{y_{0}}{y_{j}}\right)\right)=e^{-\omega_{s} \log \left(\frac{y_{0}}{y_{j}}\right)}=\left(a_{j}\right)^{\omega_{s}}
$$

So if the proportion who stay is $\mathcal{S}_{j s}$ then

$$
\log \left(\mathcal{S}_{j s}\right)=\omega_{s} \log \left(a_{j s}\right)
$$

\footnotetext{
${ }^{12}$ For example, Kennan and Walker (2011) show that attachment to home is an important determinant of internal migration decisions in the U.S.
} 


\section{Quantitative Results}

The model can be used to quantify the effects of restrictions on international migration. The main focus is on the net gains from migration (or the costs of immigration restrictions). The model also determines the number of migrants, and the real wage effects, for skilled and unskilled labor.

These quantitative implications depend on parameter values that cannot easily be inferred from the available data, although the data do provide some guidance. First, the main force driving migration is the efficiency gain when moving from one country to another. The procedure used to estimate these gains is described in Section 5.1. Next, given the gross return to migration due to the efficiency gains, the proportion of people who would actually choose to move depends on the distribution of migration costs. One way to measure this distribution is described in Section 5.2. Finally, the supply of potential migrants is estimated using labor force data from standard sources.

\subsection{Efficiency Ratios}

The efficiency ratio at skill level $s$ in country $j$ is given by

$$
a_{j s}=\frac{w_{s j}}{w_{s 0}}
$$

where $w_{s j}$ is the wage as skill level $s$ in country $j$ and $w_{s 0}$ is the corresponding wage in countries at the productivity frontier; here this is measured as the wage in Germany. These ratios are estimated using data from several sources. Data on average wages are available for OECD countries. ${ }^{13}$ Six of the new EU countries are not OECD members (Bulgaria, Cyprus, Croatia, Lithuania, Malta and Romania); for these countries, average wages are estimated as income per worker from the Penn World Table (version 8.1). ${ }^{14}$ For the case of two skill levels, average wages in country $j$ can be written as

$$
\bar{w}_{j}=\left(1-\chi_{j}\right) w_{1 j}+\chi_{j} w_{2 j}
$$

where $\chi_{j}$ is the proportion of skilled workers; here this is measured as the proportion with postsecondary education. Let $\xi_{j}=\frac{w_{2 j}}{w_{1 j}}$ be the relative wage of skilled workers in country $j$. Given estimates of relative wages (which are obtained from de Hoyos et al. (2016)), the efficiency ratios can be computed as follows. The average wage can be written as

$$
\bar{w}_{j}=\left(1-\chi_{j}\right) w_{1 j}+\chi_{j} \xi_{j} w_{1 j}
$$

Thus

$$
\frac{\bar{w}_{j}}{\bar{w}_{0}}=\left(\frac{\left(1-\chi_{j}\right)+\chi_{j} \xi_{j}}{\left(1-\chi_{0}\right)+\chi_{0} \xi_{0}}\right) \frac{w_{1 j}}{w_{10}}
$$

\footnotetext{
${ }^{13}$ See http://www.oecd.org/els/emp/AVERAGE_WAGES.pdf

${ }^{14}$ See http://www.rug.nl/research/ggdc/data/pwt/
} 


$$
a_{1 j}=\frac{\left(1-\chi_{0}\right)+\chi_{0} \xi_{0}}{\left(1-\chi_{j}\right)+\chi_{j} \xi_{j}} \frac{\bar{w}_{j}}{\bar{w}_{0}}
$$

and

$$
a_{2 j}=a_{1 j} \frac{\xi_{j}}{\xi_{0}}
$$

\subsection{Migration Costs}

Given the efficiency ratios, the simple migration model described in Section 4.8 above can be used to predict (long-run) migration flows. But in order to do this, it is necessary to specify values for the home attachment parameters $\left(\omega_{s}\right)$ for each type of worker. One way to proceed is to infer these parameters from data on the proportion of Puerto Ricans who choose to stay in Puerto Rico, even though the U.S. border is open (to Puerto Ricans), and wages in the U.S. are considerably higher. The relevant data from the 2000 Census are as follows.

Table 2: Wage Ratios and Migration Rates

\begin{tabular}{|c|c|c|}
\hline \multicolumn{2}{|c|}{ Migration from Puerto Rico to U.S. } \\
\hline Schooling & Secondary & Post-Secondary \\
\hline \hline Wage Ratio & 0.52 & 0.64 \\
\hline Migration Rate & 0.40 & 0.30 \\
\hline$\omega$ & 0.79 & 0.82 \\
\hline $\mathrm{N}$ & 718,559 & 445,435 \\
\hline
\end{tabular}

The average moving cost is the reciprocal of $\omega$. It is well known from the empirical literature that migration rates are higher for people with more education, ${ }^{15}$ but at least in the case of Puerto Rico, it is also true that the incentive to migrate is higher at higher education levels. The Puerto Rican data indicate that, as a first approximation, it is reasonable to assume that the distribution of migration costs does not differ across education levels, and the baseline estimates below assume that $\omega_{s}=.8$ for both skilled and unskilled workers. Of course, the cost of migrating from Poland to Germany may be quite different from the cost of migrating from Puerto Rico to the U.S., but it would be very difficult to measure this directly. On the other hand Kennan (2015) presents some evidence indicating that the costs of internal migration are lower for more skilled workers in the U.S. Thus it is useful to consider the implications of alternative values for the $\omega_{s}$ parameters.

\subsection{The Effective Supply of Labor}

Given that the proportion of stayers is $a^{\omega}$, the average supply of effective labor after migration (to the most productive location, where the efficiency level is normalized to 1) is $a_{j}^{\omega} \times a_{j} y_{0 s}+$ $\left(1-a_{j}^{\omega}\right) \times y_{0 s}$. Thus the increase in effective labor per person is $\left(1-a_{j}^{\omega}\right)\left(1-a_{j}\right) \frac{y_{j s}}{a_{j}}$, and the

\footnotetext{
${ }^{15}$ For example, see Wozniak (2010) and Kennan (2015).
} 
aggregate increase in effective labor due to migration is

$$
\Delta \bar{L}=\sum_{j=1}^{J}\left(1-a_{j}^{\omega}\right)\left(1-a_{j}\right) \frac{y_{j s}}{a_{j}} N_{j s}
$$

where $N_{j s}$ is the supply of labor at skill level $s$ in country $j$.

\subsection{Net Gains from Migration}

Given factor price equalization, average income per worker in country $j$ is $y_{j}=a_{j} h_{j} w$, where $h_{j}$ is the human capital of the average worker. Both $h$ and $a$ are measured in efficiency units of labor; the difference between them is that $h$ is embodied in the worker, while $a$ is embodied in the country. When a worker of type $s$ moves from $j$ to a frontier country (where $a=1$ ), the (gross) income gain is

$$
\begin{aligned}
\Delta y & =\left(1-a_{j s}\right) y_{0 s} \\
& =\frac{1-a_{j s}}{a_{j s}} y_{j s}
\end{aligned}
$$

For the average migrant, the net gain is roughly the average of this and zero, if the lowest migration cost is zero. The proportion of people who do not migrate is $a_{j s}^{\omega_{s}}$ (according to the simple model of migration decisions described in Section 4.8), so the income gain for the average person (including nonmigrants) is

$$
\bar{g}_{j s}=\frac{1}{2} \frac{\left(1-a_{j s}^{\omega_{s}}\right)\left(1-a_{j s}\right)}{a_{j s}} y_{j s}
$$

The net gains for each of the 13 countries joining the EU beginning in 2004 are shown in Figure 7. The net gains from universally open borders estimated in Kennan (2013) were roughly equivalent to doubling the income of an average worker in the average less developed country. The magnitudes of the gains from EU expansion shown in Figure 7 are somewhat less impressive, but they are still very large. For unskilled workers in the poorest countries (Romania and Bulgaria), the gains are in fact roughly equivalent to doubling average income (meaning that there is a large and permanent jump in the level of income). At the other extreme, for skilled workers in the more developed countries, the gains are small. Taking Poland as a fairly representative example, the gain is roughly $30 \%$ of income for unskilled workers, and less than $10 \%$ for skilled workers.

\subsubsection{Gains from further EU Expansion}

It is also of interest to consider the gains associated with possible further expansion of the EU, given that several additional countries are active candidates for membership. The simplest calculation assumes that skilled and unskilled workers are perfect substitutes, and infers the efficiency ratio $a_{j}$ 
Figure 7:
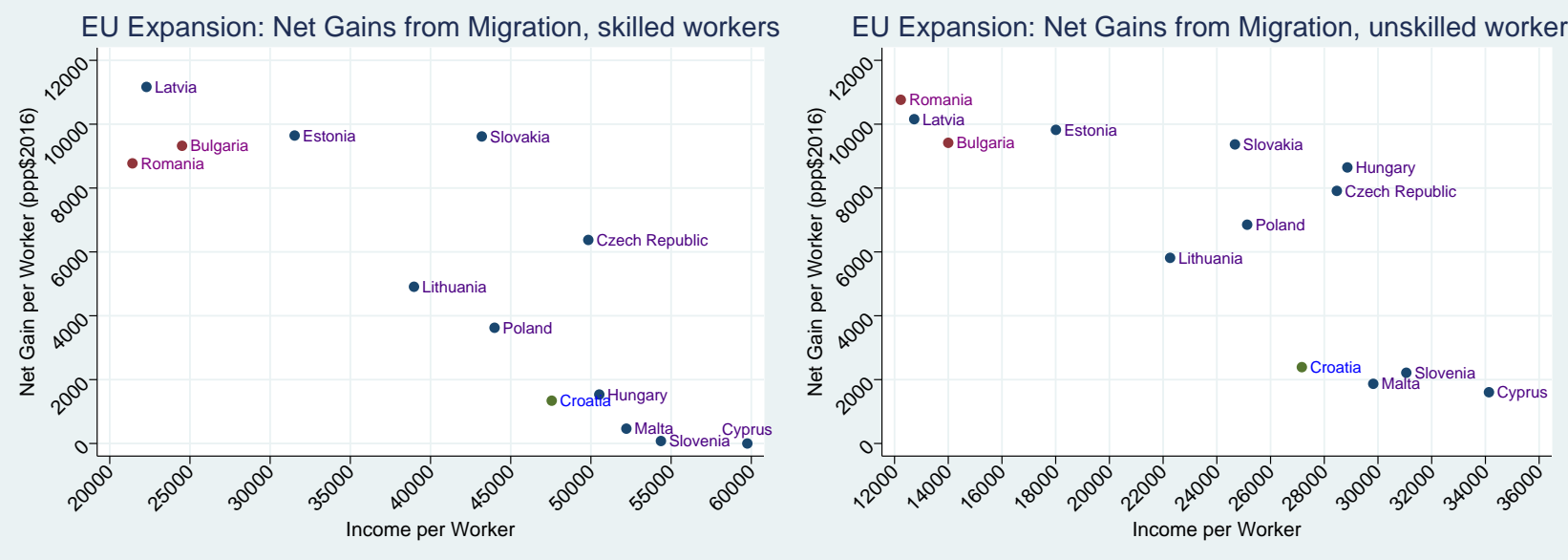

from data on GDP per worker. Illustrative results for the candidate countries using this method are shown in Figure 8 (with gains for the 13 recent member countries estimated in this way shown for comparison). The result for Serbia is much like the result for Bulgaria, and the numbers of workers are also comparable. The estimated gain per worker is relatively small for Turkey (although the magnitude is still large), but since Turkey has a large population, the total gains would be enormous.

Figure 9 shows estimates for other nearby countries, including Syria, meaning pre-war Syria. In the context of the recent refugee crisis, the results for Syria are rather striking. Even if the productivity of labor in Syria can be restored to the pre-war level, the gains from admitting Syria to the EU are estimated at about $\$ 10,000$ per annum, for the average Syrian worker (where again the average is taken over all workers, not just those who would migrate). Given the recent devastation in Syria, this is surely a conservative lower bound for the gains that would result from a policy of freely admitting Syrian migrants to the EU.

Figure 8:
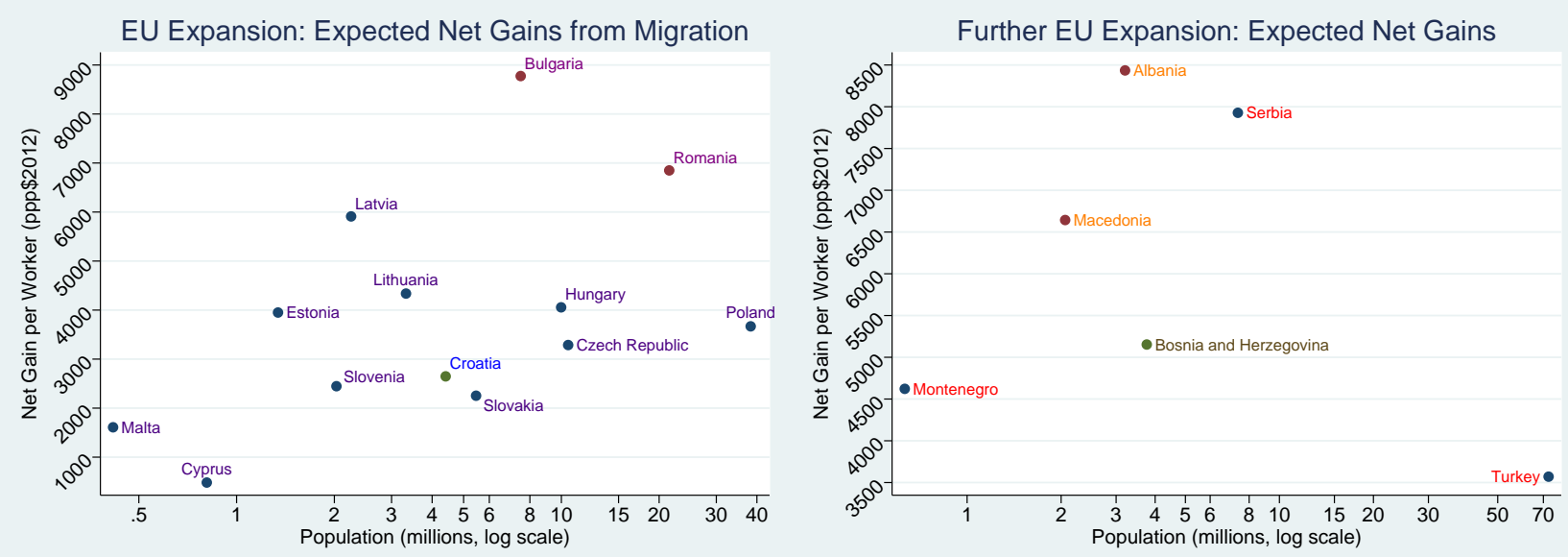
Figure 9:

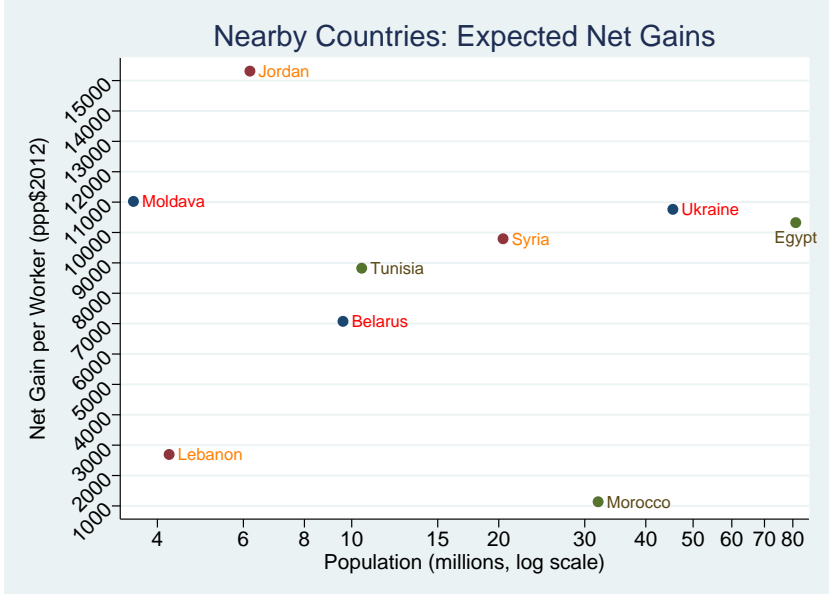

\subsection{Real Wage Changes}

When labor is treated as a homogeneous factor, the massive increase in the effective supply of labor on the world market if all borders are open implies a surprisingly small effect on real wages; this was shown in Kennan (2013). But when skilled and unskilled workers are imperfect substitutes, the real wage effects may be considerably larger for unskilled workers. Moreover, the aim here is to consider these effects in the EU context. The factor price equalization theorem assumes free trade, and this assumption is much more realistic for the EU than for the world economy as a whole. It is surely not realistic to treat the EU as a small open economy that takes product prices on the world market as given. At the other extreme, it is also unrealistic to assume that the EU is a closed economy that does not trade with the rest of the world, but this assumption will nevertheless be maintained here, on the grounds that it yields a relatively clean "worst case" analysis of real wage effects.

In order to apply these results, it is necessary to have estimates of the coefficients $\alpha_{i}$. Under the assumption that the production technology is Cobb-Douglas, and that it is the same across countries, these coefficients are equal to the factor shares (which should be the same for all countries). The estimates shown in Table 3 were obtained using data for Germany for the year 2005 .

Table 3: Factor Shares

\begin{tabular}{|c|c|c|}
\hline Schooling Years & Secondary & Post-Secondary \\
\hline \hline Workers (EU15, millions, 2004) & 112.3 & 61.2 \\
\hline Wages (Germany) & 2,957 & 4,148 \\
\hline Shares & $43.1 \%$ & $56.9 \%$ \\
\hline$\alpha$ (capital share $=.31)$ & 29.7 & $39.3 \%$ \\
\hline
\end{tabular}

The results for real wage changes due to migration are shown in Table 4. In the homogeneous labor case, doubling the labor endowment had a relatively small effect on the real wage. But the 
unskilled labor share is small, and this means that almost all of the change in the unskilled labor endowment passes through to the real wage. The estimated change in the endowment is that it increases by about $15 \%$, and the real wage then falls by about $6 \%$. On the other hand, there is very little change in the real wage of skilled labor. The ratio of skilled labor to capital falls substantially, but this is largely offset by the increase in the ratio of unskilled to skilled labor ${ }^{16}$

Table 4: Real Wage Effects

\begin{tabular}{|c|c|c|}
\hline Schooling & Secondary & Post-Secondary \\
\hline Immigration (millions) & 16.63 & 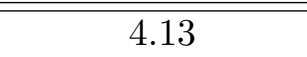 \\
\hline Percentage Increase in Effective Labor & $14.8 \%$ & $6.7 \%$ \\
\hline Real Wage Change & $-6.3 \%$ & $+0.8 \%$ \\
\hline Employment in EU15 (millions) & 112.3 & 61.2 \\
\hline Employment in EU+13 Countries & 32.4 & 11.0 \\
\hline
\end{tabular}

\subsubsection{Sensitivity of Real Wage Changes to Elasticities of Substitution}

The above calculations are based on unit elasticities of substitution. The standard view is that the elasticity of substitution across skill groups is a good deal higher than unity (see Katz and Murphy (1992), Ottaviano and Peri (2012), Card (2012), and di Giovanni et al. (2014)). Computing the effects for the CES case requires more work - it is necessary to solve the equilibrium equations numerically. The point is that a higher elasticity means that unskilled workers would gain less from an increase in the skilled labor endowment.

If preferences are symmetric over goods, the unskilled real wage is given by

$$
w_{U}^{*}=\frac{w_{U}}{p_{0}}
$$

and

$$
\left(\frac{p_{0}}{w_{U}}\right)^{1-\sigma}=\alpha_{0}^{\sigma}\left(\frac{v}{w_{U}}\right)^{1-\sigma}+\left(1-\alpha_{0}\right)^{\sigma}\left(\frac{W_{0}}{w_{U}}\right)^{1-\sigma}
$$

so

$$
\left(w_{U}^{*}\right)^{\sigma-1}=\alpha_{0}^{\sigma}\left(\frac{w_{U}}{v}\right)^{\sigma-1}+\left(1-\alpha_{0}\right)^{\sigma}\left(\frac{w_{U}}{W_{0}}\right)^{\sigma-1}
$$

Also

$$
W_{0}^{1-\zeta}=\gamma_{0}^{\zeta}\left(w^{S}\right)^{1-\zeta}+\left(1-\gamma_{0}\right)^{\zeta}\left(w^{U}\right)^{1-\zeta}
$$

so

\footnotetext{
${ }^{16}$ If only skilled workers are allowed to migrate, the real wage of unskilled workers increases by $15 \%$.
} 


$$
\left(\frac{W_{0}}{w^{U}}\right)^{1-\zeta}=\gamma_{0}^{\zeta}\left(\frac{w^{S}}{w^{U}}\right)^{1-\zeta}+\left(1-\gamma_{0}\right)^{\zeta}
$$

and

$$
\left(w_{U}^{*}\right)^{\sigma-1}=\alpha_{0}^{\sigma}\left(\frac{w_{U}}{v}\right)^{\sigma-1}+\left(1-\alpha_{0}\right)^{\sigma}\left(\gamma_{0}^{\zeta}\left(\frac{w^{S}}{w^{U}}\right)^{1-\zeta}+\left(1-\gamma_{0}\right)^{\zeta}\right)^{\frac{\sigma-1}{\zeta-1}}
$$

These results can be applied in examples by restating the factor price ratios in terms of income ratios $\left(x_{1}, x_{2}\right)$ and endowments $\left(K_{0}, S_{0}, U_{0}\right)$, and solving the equilibrium equations to obtain the equilibrium values of $x$ for given endowments. Thus

$$
\left(w_{U}^{*}\right)^{\sigma-1}=\alpha_{0}^{\sigma}\left(x_{2} \frac{K_{0}}{U_{0}}\right)^{\sigma-1}+\left(1-\alpha_{0}\right)^{\sigma}\left(\gamma_{0}^{\zeta}\left(\frac{x_{1}}{x_{2}} \frac{U_{0}}{S_{0}}\right)^{1-\zeta}+\left(1-\gamma_{0}\right)^{\zeta}\right)^{\frac{\sigma-1}{\zeta-1}}
$$

Similarly, the skilled real wage is given by

$$
\left(w_{S}^{*}\right)^{\sigma-1}=\alpha_{0}^{\sigma}\left(x_{1} \frac{K_{0}}{S_{0}}\right)^{\sigma-1}+\left(1-\alpha_{0}\right)^{\sigma}\left(\gamma_{0}^{\zeta}+\left(1-\gamma_{0}\right)^{\zeta}\left(\frac{x_{2}}{x_{1}} \frac{S_{0}}{U_{0}}\right)^{1-\zeta}\right)^{\frac{\sigma-1}{\zeta-1}}
$$

Examples are given in Table 5.

Table 5: Alternative Substitution Elasticities
\begin{tabular}{|c|c|c|c|}
\hline & & \multicolumn{2}{|c|}{ Schooling Years } \\
\hline & & Secondary & Post-Secondary \\
\hline \hline & \multicolumn{3}{|c|}{ Effective Labor Change } \\
\hline & & $21.7 \%$ & $11.1 \%$ \\
\hline \multirow{3}{*}{$\sigma=\frac{1}{2}$} & $\zeta$ & \multicolumn{2}{|c|}{ Real Wage Changes } \\
\cline { 2 - 4 } & $\frac{1}{2}$ & $-12.4 \%$ & $1.3 \%$ \\
& 1 & $-9.5 \%$ & $-2.7 \%$ \\
& 2 & $-8.1 \%$ & $-4.7 \%$ \\
\hline & $\frac{1}{2}$ & $-9.3 \%$ & $5.0 \%$ \\
\hline$\sigma=1$ & 1 & $-6.3 \%$ & $0.8 \%$ \\
\hline & 2 & $-4.8 \%$ & $-1.2 \%$ \\
\hline \multirow{2}{*}{} & $\frac{1}{2}$ & $-7.7 \%$ & $6.7 \%$ \\
\cline { 1 - 1 }$\sigma=2$ & 1 & $-4.7 \%$ & $2.5 \%$ \\
\hline & 2 & $-3.1 \%$ & $0.5 \%$ \\
\hline
\end{tabular}

The real wage effects are not very sensitive to deviations from the benchmark Cobb-Douglas technology. As the elasticity of substitution between capital and the labor composite $(\sigma)$ increases, the real wages effects are diminished for both skill levels. As the elasticity of substitution between skilled and unskilled labor $(\zeta)$ increases, the real wages effects are more favorable for unskilled workers, at the expense of skilled workers. 


\section{Conclusion}

In Kennan (2013) it was shown that the potential gains from open borders are very large: if all of the developed countries dropped all legal restrictions on immigration, the gains would be roughly comparable to a doubling of the income of the average person in a less developed country. The European Union has actually implemented an open borders regime, and the expansion of the EU to include many large countries with relatively low wages provides some evidence on the extent to which these gains are actually realized. Here the potential gains are quantified country by country, for the countries which actually joined the EU since 2004, and also for countries that are candidates for membership, as well as other countries in the neighborhood. The estimated gains are shown in Figures 8 and 9. In the case of unskilled workers in Poland, for example, the estimated average gain is about $30 \%$ of income, or about $\$ 7,000$ per worker per year; this is net of migration costs, and the average is taken over all Polish workers (the average gain for the people who actually migrate is much higher). Although these gains are certainly substantial, they are not as large as the gains reported in Kennan (2013), simply because the measured labor productivity differences are not on the same scale as the difference between productivity levels in countries like India, compared with countries like the U.S.

These estimates are based on a model in which free trade in product markets implies factor price equalization, with the important qualification that although real wages are equalized across countries even when labor is immobile, this applies to wages measured in efficiency units; actual wage measures reflect cross-country differences in the productivity of labor. Removing restrictions on labor mobility affects equilibrium real wages to the extent that workers move to countries where they are more productive, thereby reducing capital-labor ratios. The model is used to quantify the real wage effects associated with increased labor mobility due to expansion of the European Union. Even though the predicted migration flows are large in relation to the number of workers in the sending countries, the estimated real wage effects are surprisingly small, even under the assumption that capital is held constant. More generally, a reduction in the capital-labor ratio that causes a fall in the real wage, also causes an increase in the return to investment in capital; these are in fact two sides of the same coin. ${ }^{17}$ Thus in the long run (assuming a constant returns technology) even large migration flows do not depress real wages. Political opposition to free migration of labor is based to some extent on the prediction that immigration depresses real wages in the host country. The analysis in this paper is based on a model that determines real wages in general equilibrium (as opposed to a model in which changes in the quantity of labor supplied merely generate movements along a marginal product curve for a single good). Any credible prediction regarding the long-run effects of immigration on real wages requires a fully specified theory of how wages are determined in general equilibrium. The theory in this paper, when used to quantify the long-run real wage

\footnotetext{
${ }^{17}$ It is also important to recognize that removing restrictions on international labor mobility is likely to increase the return to investment in human capital, implying that the long-run gains are likely to be considerably higher than the gains estimated in this paper, which takes the distribution of skills as given.
} 
effects of immigration, provides no support for the idea that immigration depresses real wages.

\section{Appendix: Uniqueness}

The proof of uniqueness involves the following steps, each of which is quite straightforward.

1. Every solution of the market-clearing equations is associated with a competitive equilibrium.

2. Every competitive equilibrium is Pareto optimal.

3. Every Pareto optimal allocation maximizes the utility of a consumer who owns everything.

4. If two allocations are Pareto optimal, they must have the same total output vector, because preferences are strictly convex.

5. The production function for each good is strictly quasiconcave.

6. If two Pareto optimal production plans yield the same output, they must use the same input vectors.

These steps are discussed in turn.

1. Suppose that $x$ solves the market-clearing equations (4). Normalize the price of capital so that $v=1$, and set wages as

$$
\left(w^{S}, w^{U}\right)=\bar{K}\left(\frac{x_{1}}{\bar{S}}, \frac{x_{2}}{\bar{U}}\right)
$$

and set product prices equal to the production costs, meaning that

$$
p_{r}^{1-\sigma}=\alpha_{r}^{\sigma}+\left(1-\alpha_{r}\right)^{\sigma} W_{r}^{1-\sigma}
$$

with

$$
W_{r}^{1-\zeta}=\gamma_{r}^{\zeta}\left(w^{S}\right)^{1-\zeta}+\left(1-\gamma_{r}\right)^{\zeta}\left(w^{U}\right)^{1-\zeta}
$$

Using these factor and product prices, set the quantities of the consumption goods so that

$$
p_{r} Q_{r}=\theta_{r}\left(w^{S} \bar{S}+w^{U} \bar{U}+\bar{K}\right)
$$

and set the input quantities so that

$$
\begin{aligned}
& \left(\frac{Q_{r}}{K_{r}}\right)^{\rho}=\alpha_{r}+\left(1-\alpha_{r}\right)\left(\frac{W_{r}}{v} \frac{\alpha_{r}}{1-\alpha_{r}}\right)^{1-\sigma} \\
& \left(\frac{Q_{r}}{L_{r}}\right)^{\rho}=\alpha_{r}\left(\frac{v}{W_{r}} \frac{1-\alpha_{r}}{\alpha_{r}}\right)^{1-\sigma}+\left(1-\alpha_{r}\right)
\end{aligned}
$$

This fully specifies the equilibrium quantities and (relative) prices. It is easy to check that the consumption and production choices are optimal at these prices, and the factor markets clear because $x$ solves the market-clearing equations. 
2. This step is just the first welfare theorem. ${ }^{18}$

3. Given that preferences are homothetic, and identical for all agents, the competitive equilibrium must maximize the utility of a consumer who has these preferences and owns everything. In any competitive equilibrium, by homotheticity, there is a number $\beta^{i}$ for each consumer $i$ such that the individual consumption plans are given by

$$
q^{i}=\beta^{i} Q
$$

where $Q$ is the equilibrium aggregate output vector. The utility function representing a homothetic preference ordering can be chosen so that it is linear homogeneous, implying that

$$
u\left(q^{i}\right)=\beta^{i} u(Q)
$$

Then if $u(\hat{Q})>u(Q)$ for some feasible aggregate output vector $\hat{Q}$, and if this output is divided over consumers so that $\hat{q}^{i}=\beta^{i} \hat{Q}$, then

$$
\begin{aligned}
u\left(\hat{q}^{i}\right) & =\beta^{i} u(\hat{Q}) \\
& >u\left(q^{i}\right)
\end{aligned}
$$

which gives a contradiction. Therefore if $Q$ is the aggregate output vector in a competitive equilibrium, then $u(Q)$ is maximal over the set of feasible output vectors.

4. From step 3, any Pareto optimal allocation maximizes the utility function over the set of feasible aggregate consumption plans, and since the feasible set is convex and the utility function is strictly quasiconcave, there is a unique utility-maximizing consumption vector.

5. Any constant-returns CES production function with a nonnegative and finite elasticity of substitution is concave and strictly quasiconcave. Suppose $f: \mathbb{R}^{n} \rightarrow \mathbb{R}^{k}$ and $g: \mathbb{R}^{m} \rightarrow \mathbb{R}^{\ell}$ are strictly quasiconcave functions, and suppose $h: \mathbb{R}^{k+\ell} \rightarrow \mathbb{R}$ is a strictly increasing and strictly quasiconcave function, and let $H(x, y)=h(f(x), g(y))$ for $x \in \mathbb{R}^{n}$ and $y \in \mathbb{R}^{m}$. The question is whether $H$ is strictly quasiconcave. Take two distinct points $\left(x^{a}, y^{a}\right)$ and $\left(x^{b}, y^{b}\right)$ in $\mathbb{R}^{n} \times \mathbb{R}^{m}$, with $X^{a}=f\left(x^{a}\right)$ and $X^{b}=f\left(x^{b}\right)$, and $Y^{a}=g\left(y^{a}\right)$ and $Y^{b}=g\left(y^{b}\right)$. Let $\bar{x}=$ $\delta x^{a}+(1-\delta) x^{b}$ and $\bar{y}=\delta y^{a}+(1-\delta) y^{b}$ and $\bar{X}=\delta X^{a}+(1-\delta) X^{b}$ and $\bar{Y}=\delta Y^{a}+(1-\delta) Y^{b}$, with $\delta \in(0,1)$. First suppose $\left(X^{a}, Y^{a}\right) \neq\left(X^{b}, Y^{b}\right)$. Then since $h$ is strictly quasiconcave,

\footnotetext{
${ }^{18}$ The proof can be recited so as to emphasize that this step is elementary. If there is an alternative allocation that is a Pareto improvement, the value of aggregate consumption at the equilibrium prices is strictly larger in this alternative allocation (someone is doing strictly better, so the value of this person's consumption bundle must be strictly greater, or it would have been chosen before; and no one is doing worse, and if they could have achieved this by spending less money, then local nonsatiation implies that they could have done better). The value of consumption is the value of net production plus the value of the endowment. But the value of net production can't be higher in the alternative plan, because if it were, some producer was not maximizing profit. And since the value of the endowment is unchanged, this gives a contradiction.
} 
we have

$$
h(\bar{X}, \bar{Y})>\min \left(h\left(X^{a}, Y^{a}\right), h\left(X^{b}, Y^{b}\right)\right)
$$

By concavity of the functions $f$ and $g$ we have

$$
\begin{aligned}
& f(\bar{x}) \geq \bar{X} \\
& g(\bar{y}) \geq \bar{Y}
\end{aligned}
$$

Since $h$ is increasing, this implies

$$
h(f(\bar{x}), g(\bar{y})) \geq h(\bar{X}, \bar{Y})
$$

Thus

$$
\begin{aligned}
H(\bar{x}, \bar{y}) & =h(f(\bar{x}), g(\bar{y})) \\
& \geq h(\bar{X}, \bar{Y}) \\
& >\min \left(h\left(X^{a}, Y^{a}\right), h\left(X^{b}, Y^{b}\right)\right) \\
& =\min \left(H\left(x^{a}, y^{a}\right), H\left(x^{b}, y^{b}\right)\right)
\end{aligned}
$$

Now suppose $\left(X^{a}, Y^{a}\right)=\left(X^{b}, Y^{b}\right)$. Either $x^{a} \neq x^{b}$, which implies $f(\bar{x})>\min \left(f\left(x^{a}\right), f\left(x^{b}\right)\right)=$ $\bar{X}$, or $y^{a} \neq y^{b}$ which implies $g(\bar{y})>\bar{Y}$, and in either case $H(\bar{x}, \bar{y})>h(\bar{X}, \bar{Y})$ since $h$ is strictly increasing, and $h(\bar{X}, \bar{Y})=H\left(x^{a}, y^{a}\right)=H\left(x^{b}, y^{b}\right)$. Thus in any case

$$
H(\bar{x}, \bar{y})>\min \left(H\left(x^{a}, y^{a}\right), H\left(x^{b}, y^{b}\right)\right)
$$

which proves that $H$ is strictly quasiconcave.

6. If two Pareto optimal production plans yield the same output vector, then any convex combination of these plans is also feasible, and yields at least as much output of each good; and if the two plans involve distinct input vectors for some product, the convex combination yields a strictly greater quantity of this product, since the production function for each good is strictly quasiconcave (by step 4).

\section{References}

Bhagwati, J. N. (1984). Incentives and disincentives: International migration. Weltwirtschaftliches Archiv 120(4), 678-701. 2

Borjas, G. (2003). The labor demand curve is downward sloping: Reexamining the impact of immigration on the labor market. The Quarterly Journal of Economics 118(4), 1335-1374. 7 
Card, D. (2001). Immigrant inflows, native outflows, and the local labor market impacts of higher immigration. Journal of Labor Economics 19(1), 22-64. 7

Card, D. (2012). Comment: The elusive search for negative wage impacts of immigration. Journal of the European Economic Association 10(1), 211-215. 24

Caselli, F. and J. Feyrer (2007). The marginal product of capital. The Quarterly Journal of Economics 122(2), 535-568. 3

Clemens, M. A. (2011). Economics and emigration: Trillion-dollar bills on the sidewalk? Journal of Economic Perspectives 25(3), 83-106. 7

Colas, M. (2016, May). Dynamic responses to immigration. University of Wisconsin-Madison. 7

Davis, D. R. and D. E. Weinstein (2004). The factor content of trade. In E. K. Choi and J. Harrigan (Eds.), Handbook of International Trade. Wiley-Blackwell. 3

de Hoyos, R., J. Kennan, and R. Lessem (2016, May). Returns to investments in human capital, within and across countries. 19

di Giovanni, J., A. A. Levchenko, and F. Ortega (2014, December). A global view of cross-border migration. Journal of the European Economic Association. forthcoming. 24

Dixit, A. K. and J. E. Stiglitz (1977). Monopolistic competition and optimum product diversity. The American Economic Review 67(3), pp. 297-308. 3

Goldberg, P. K. and N. Pavcnik (2007, March). Distributional effects of globalization in developing countries. Journal of Economic Literature 45(1), 39-82. 3

Hamilton, B. and J. Whalley (1984, 1984/2//). Efficiency and distributional implications of global restrictions on labour mobility: Calculations and policy implications. Journal of Development Economics 14(1), 61-75. 2, 3

Iregui, A. M. (2005). Efficiency gains from the elimination of global restrictions on labour mobility: An analysis using a multiregional cge model. In Poverty, International Migration and Asylum. Palgrave Macmillan. 2

Katz, L. F. and K. M. Murphy (1992, February). Changes in relative wages, 1963-1987: Supply and demand factors. Quarterly Journal of Economics 107, 35-78. 24

Kennan, J. (2013, April). Open borders. Review of Economic Dynamics 16, L1-L13. 3, 7, 18, 21, 23,26

Kennan, J. (2015, April). Spatial variation in higher education financing and the supply of college graduates. Working Paper 21065, National Bureau of Economic Research. 20 
Kennan, J. and J. R. Walker (2011). The effect of expected income on individual migration decisions. Econometrica 79(1), 211-251. 5, 18

Klein, P. and G. Ventura (2007). Tfp differences and the aggregate effects of labor mobility in the long run. The B.E. Journal of Macroeconomics 7(1), 1-36. 7

Klein, P. and G. Ventura (2009). Productivity differences and the dynamic effects of labor movements. Journal of Monetary Economics 56(8), 1059 - 1073. 3, 7

Krugman, P. (1980). Scale economies, product differentiation, and the pattern of trade. The American Economic Review 70(5), pp. 950-959. 3

Melitz, M. J. (2003). The impact of trade on intra-industry reallocations and aggregate industry productivity. Econometrica $71(6), 1695-1725.3$

Moses, J. W. and B. Letnes $(2004,10)$. The economic costs to international labor restrictions: Revisiting the empirical discussion. World Development 32(10), 1609-1626. 2

Ottaviano, G. I. P. and G. Peri (2012). Rethinking the effect of immigration on wages. Journal of the European Economic Association 10(1), 152-197. 24

Piyapromdee, S. (2015, June). The impact of immigration on wages, internal migration and welfare. Technical report, UCL. 7

Storesletten, K. (2000). Sustaining fiscal policy through immigration. Journal of Political Economy $108(2), 300-323.7$

Trefler, D. (1993). International factor price differences: Leontief was right! The Journal of Political Economy $101(6)$, pp. 961-987. 3

Wozniak, A. (2010). Are college graduates more responsive to distant labor market opportunities? Journal of Human Resources 45(4), 944-970. 20 